Article

\title{
Institutionalizing Strong Sustainability: A Rawlsian Perspective
}

\section{Konrad Ott}

Christian-Albrechts-Universität zu Kiel, Philosophisches Seminar, Leibnizstr. 4, 24118 Kiel, Germany; E-Mail: ott@philsem.uni-kiel.de; Tel.: +49-431-880-3920; Fax: +49-431-880-2828

Received: 17 October 2013; in revised form: 12 February 2014 / Accepted: 13 February 2014 / Published: 21 February 2014

\begin{abstract}
The article aims to provide some ethical orientation on how sustainability might be actualized by institutions. Since institutionalization is about rules and organization, it presupposes ideas and concepts by which institutions can be substantiated. After outlining terminology, the article deals with underlying ethical and conceptual problems which are highly relevant for any suggestions concerning institutionalization. These problems are: (a) the ethical scope of the sustainability perspective (natural capital, poverty, sentient animals), (b) the theory of justice on which ideas about sustainability are built (capability approach, Rawlsianism), and (c) the favored concept of sustainability (weak, intermediate, and strong sustainability). These problems are analyzed in turn. As a result, a Rawlsian concept of rule-based strong sustainability is proposed. The specific problems of institutionalization are addressed by applying Rawls's concept of branches. The article concludes with arguments in favor of three transnational duties which hold for states that have adopted Rawlsian strong sustainability.
\end{abstract}

Keywords: theories of justice; strong sustainability; institutionalization; deliberative democracy

\section{Introduction}

\subsection{The Actualization of Sustainability and Overview}

Let us assume for the sake of the argument which is being presented in this article that reasonable ideas, as sustainability, are in themselves bound to become actualized via concepts, institutions, and policy making. This general perspective is clearly inspired by Hegel's idea of actualization ("Verwirklichung") [1]. The term "concept" refers to patterns of arguments by which the general meaning of an idea is specified. Ideas being actualized via concepts come into close contact with many 
realities (states of affair) of a non-ideal world that may support or hinder such actualization. The Western concept of progress has been about actualization of ideas, such as turning rule of law, human rights, democracy, peace, women's liberation and material prosperity into societal realities within the course of time. Sustainability has been among those ideas since the 18th century, but it was neglected over the century in which economic growth became predominant (1870-1970). The intellectual rediscovery of sustainability had its origin in the 1970 s. This rediscovery split into a theoretical discourse and a public political debate. Meanwhile, the idea of sustainability became widely acknowledged. Institutionalization of sustainability, however, still lags behind other societal institutions by which achievements of modernity are actualized. The article addresses the question how this gap between the very idea and institutions of sustainability might be bridged. Such bridging is not a matter of mere technical application, but requires in itself some philosophical reflection.

The article is organized as follows. Some definitions are given in the next subsection. The following section addresses moral problems in the idea of sustainability. Section 3 reflects on the theory of justice which underlies the idea of sustainability. The argument is that a Rawlsian approach to justice is superior to the capability approach in several respects, especially with terms of institutionalization. In Section 4, the concept of "strong" sustainability as rule-based and open for institutionalization both in terms of rules and organizations is defined [2-4]. This section also addresses the problem of how to specify more general rules and how to relate rules and political objectives. The problem of institutionalization is, finally, addressed in Section 5, illustrating a Rawlsian perspective, especially with regard to the concept of branches that work within a well-ordered society. Before making final conclusions, the last section argues that states which have adopted Rawlsian strong sustainability should also adopt some transnational obligations.

\subsection{Types and Functions of Institutions}

The term "institution" refers to societal orders of different kinds, especially systems of rules, but also organizations, boards and offices which presume to be legitimate. I follow the definition as given by Rawls: "By an institution I understand a public system of rules which defines offices and positions with their rights and duties, powers and immunities, and the like" [5]. Constitutions are a paradigm case of basic societal institutions. Ordering human affairs must be done by rules and by comprehensive systems of rules ("Regelwerke") which persons have to follow prima facie in specific situations. There are different types of rules, as technical, moral and legal rules or customs. Analyses of single components and types of rules are given by von Wright [6]. Institutions have the general function to liberate persons from considering how to act on a case-by-case basis. They provide orientation and they stabilize interpersonal expectations. Institutions and organizations are open for revision and reform, but they also have inertia of their own and they often last long. Many existing institutions may work, in fact, as barriers and obstacles to sustainable development since they support a growthoriented system of production and consumption that depletes natural resources on a global scale. The term "sustainable development" is about reforming institutions toward sustainability (A comprehensive analysis of institutions in their relationship to sustainability is given in Klauer et al. [7]. It is argued by Klauer et al. [7] that policies of sustainability require a prudent reformist agenda of how to transform 
institutions democratically. A more radical alternative to this reformist approach to institutions is to be found in the agenda of "non-reformist reforms" as to be found in the degrowth movement [8]).

The presumption of legitimacy which underlies institutions can be substantiated in many ways. The article rests on suppositions about democratic legitimacy. Under this supposition, rules are neither taboos nor commands being given by authorities. With respect to a public system of rules, the authors ("citizens") and the followers of rules ("private persons") can and should become identical in discursive and deliberative settings. Only democracy, as an institution in itself, can resolve the problem of legitimacy of institutions under modern conditions [9]. This assumption is in accordance with Rawlsianism. The idea of democratic self-determination (political freedom) is presupposed in any debate on sustainable development. Thus, it is far better from a philosophical point of view to analyze our modern system of moral and political ideas (as liberty, peace, democracy, and pursuit of happiness) as interdependent presuppositions than to press ideas into other ideas. If so, democracy is more than just institutional capital that should be sustained over time.

Besides rules, organizations of different kinds (such as offices, companies, trade unions, political parties, boards, agencies, clubs, courts, parliaments and so on) can be defined as another type of institution. I prefer to distinguish between rules as primary institutions and organizations as secondary institutions. This is in accordance with the definition of Rawls. Organizations, of course, have specific rules of their own. By way of example: democracy is an institution; political parties are organizations; laws are institutions, courts are institutionalized organizations. The term "policy making" refers to (democratic) legislation, agenda-setting, governance, and implementation. The concept of sustainability defines the realms of policies which are relevant to sustainable development. Contemporary policy making works within a multi-level system of politics, ranging from international regimes to local authorities. I will address briefly such a system in the final section.

\section{The Moral Scope of Sustainability}

\subsection{The Focal Perspective of Sustainability}

From a historical perspective, the idea of "Nachhalt" emerges within German forestry ([10]). This idea recognizes the very possibility that a crucial natural resource (timber-providing woods) can be utilized in a way that degrades and destroys the resource base over the course of time. This had been the case in German forests during the 18th century when production and heating strongly relied on timber. Sustainability originated as an idea that constrained the contemporary utilization of natural resources out of duty to future generations or "posterity," as Carlowitz put it [10]. If the history of an idea intrinsically belongs to its conceptual meaning, both crucial aspects ("conceptual moments") are present in Carlowitz: (a) long-term intergenerational perspective, (b) proper ("wise") utilization of natural resources (natural capital) are constitutive ("focal") for the concept of sustainability. I dub this long-term orientation with respect to natural resources "the focal perspective of sustainability" (FP). This focal perspective is directed against the negligence of long-term environmental protection, as compared to the more immediately pressing societal, economic and even moral problems which are raised by organized stakeholder groups. It is directed against all kinds of myopia, seen as a natural inclination of humans. FP gives special attention to natural resources and environmental media 
because their overutilization and depletion is highly likely in an industrial system of production and consumption that intends (a) to fulfill the many aspirations in modern societies ("social welfare"); and (b) to secure monetary returns of investments in stocks of manmade capital ("profit"). Thus, FP relies on a large "environmental lesson" which is part of the overall narrative of industrial modernity.

FP was not new to forestry and agriculture, but it was quite new to philosophical ethics. FP has two ethical dimensions: (a) the deontology of moral commitments to members of future generations, (b) the axiology of resources and goods within nature that contribute to societal welfare and the good lives of individuals. Meanwhile, a field of "future ethics" has emerged and been established which addresses both dimensions. "Future ethics" analyzes the philosophical puzzles in long-term responsibility, the relationship between future rights and contemporary obligations, and issues of risk and uncertainty. Climatic change, disposal of nuclear waste, extinction of species, degradation of soils and forests, overfishing, desertification, and the like are paradigm cases within FP. Given such ethical puzzles and practical topics, current FP has a high level of complexity on its own. Even one paradigm case within FP, as climatic change, has reached a level of complexity (mitigation, adaptation, carbon management, solar radiation management) which is hard to deal with even by large epistemic communities, such as IPCC.

\subsection{Challenges and Limits of FP}

There are reasons to add more ethical topics to the concept of sustainability. Two crucial topics are (1) contemporary (absolute) poverty and (2) inherent moral value for natural beings ("demarcation problem" [11]). Both topics are not mere external add-ons to FP but they emerge by reflection of FP, widening its scope from within and, by doing so, adding complexity to the overall ethics of sustainability. Both topics necessitate FP to broaden its scope but they can also be overwhelming and even dissolutive for FP. In any case, one has to understand the underlying moral necessitation of this tendency to focus on poverty and animal welfare in order to reflect it critically within a theory of sustainability. Such reflection is highly significant and even decisive for the institutional design of sustainability policies (Sections 5 and 6).

It seems, first, an incoherent moral position to focus on intergenerational fairness exclusively while neglecting absolute and extreme poverty in our contemporary interconnected world. Absolute poverty implies that basic needs (such as nourishment, shelter, sanitation) cannot be properly met on a daily basis. It implies misery and deprivation. The famous definition of sustainable development given by WCED [12] refers to fulfillment of present and future human needs, especially to the basic needs of "the world's poor, to which overriding priority should be given" [13]. (Nature is mentioned as follows in the report: "At a minimum, sustainable development must not endanger the natural systems that support life on Earth: the atmosphere, the waters, the soils, and the living beings" [14]. This conceptual connection between combating absolute poverty and FP has been constitutive to the debate about sustainable development since WCED.) There are strong moral intuitions that speak in favor of such priority. The wicked relationship between the FP and the reduction of absolute contemporary poverty can be interpreted ethically as mutually constraining obligations [15]. Under this resolution, courses of action are sustainable only if the long-term protection of natural resources (or natural capitals) will not hamper poverty alleviation; and poverty reduction shall not impair the protection and preservation of 
natural resources. Such mutual constraints can presume to take the "and" in the formula "inter- and intragenerational justice" seriously. Environmental protection is a "proviso" with respect to the reduction of absolute poverty - and such reduction is a "proviso" with respect to environmental protection. This dual proviso, then, should be properly institutionalized.

Poverty is, however, a wicked problem on different scales (global, national, regional) which must be addressed on its own terms with scientific rigor with respect to causes, drivers, development over time, and the like. If so, poverty absorbs much of the scarce moral attentiveness. One has to distinguish relative from absolute poverty and to specify extreme poverty within absolute poverty. Urban poverty has another shape than rural poverty. Poverty has specific gender aspects. The prospects to escape poverty are different in different regions and the escape from severe poverty might come at the price of bad labor conditions, migration into urban zones, and so on. Since absolute poverty is concentrated in some regions (Sub-Saharan Africa, India), cultural knowledge is required to understand how single societies address local poverty. If, according to WCED, fulfillment of basic needs deserves overriding moral priority, such overriding may imply a shift in sustainability theories away from the original FP. Since absolute and extreme poverty is pressing and urgent, since poverty and wealth are mediated in many ways by economic institutions, as markets, and since poverty can be easily moralized and politicized, the original FP may be gradually dominated and overwhelmed by the political economy of poverty (and inequality) within sustainability discourse. Thus, the original FP of sustainability might shift towards institutions and policy agendas, as development aid that addresses poverty reduction. It might be argued that reduction of contemporary poverty and of excessive inequality within nations and between nations may improve the long-term conditions for addressing environmental problems. Poverty reduction and limitation of economic inequalities, then, would lead to decent sustainable livelihoods which gradually relieve the pressure on the natural environment. This line of argument implies another shift in moral attentiveness towards issues of redistribution, financing transfers, taxation and the like. If this argument is valid, intragenerational equity deserves priority. If this argument is, however, flawed (or based on wishful thinking) it may undermine the original FP. The present, then, would again triumph over the future. What we see at the moment, is, roughly, constancy in extreme poverty in absolute numbers within a growing human population and the emergence of a global lower middle-class with many consumptive aspirations. Thus, the win-win argument must be seen with critical eyes.

Second, it must be asked whether sustainability is a purely anthropocentric concept. Even if all the sophisticated problems of a future ethics might have found a proper resolution within a reflective equilibrium (which is not the case) the demarcation problem still remains. Again, the moral question emerges from within FP itself: Why stop at intergenerational fairness and not include natural beings in the moral community? Why should we have moral commitments with respect to posterity and not with respect to sentient animals which suffer right now within the industrialized system of domestication or suffer in the wild?

The demarcation problem is about the attribution of inherent moral value to specific beings. The demarcation debate in environmental ethics has resulted in different solutions (as anthropocentrism, sentientism, biocentrism, ecocentrism, and holism) which compete against each other. After decades of ethical debate, the common ethical solution of the demarcation problem is clearly sentientism. According to sentientism, inherent moral value should be attributed to any living being which is 
capable of experiencing pleasure, joy, pain, suffering, frustration, and other conscious states. However, sentientism is in itself full of wicked moral problems which are addressed in the field of animal ethics (for instance, obligations to wildlife). I only mention two of them. If, first, one adopts sentientism and connects it to FP, the problem of future sentient animals must be treated within a concept of sustainability. Thus, what about future polar bears in the age of climatic change and what about future dolphins in a global fishery? The second problem is about suffering that occurs in natural food webs since there are carnivores around in the wild and wild animals can starve and freeze to death. Any extension of animal ethics into the wild opens a can of moral worms. Its relation to FP and to institutionalization is highly unclear. Nussbaum has, from the perspective of the capability approach, argued that humans are morally obliged to reduce suffering in the wild (Nussbaum, 2006 [16]). It is unclear, however, whether proponents of the capability approach are committed to Nussbaum's (quite strange or even absurd) animal ethics; institutionalization of Nussbaum's animal ethics would result in policing nature and in interfering in natural food webs. Stringently, such ways of "policing nature" would have to be applied not only to tigers, but also to owls, bears, and sharks.

Since both the problem of contemporary absolute poverty and the demarcation problem emerge on reflection from within the focal perspective, moral persons cannot simply abstract them away. A comprehensive ethics of sustainability, then, would be a moral cluster composed of the reduction of absolute poverty, animal ethics including wildlife, and original FP. This moral cluster, then, should be institutionalized properly. But both extensions tend to overburden FP. If so, there might be pragmatic reasons to conceive FP as centerpiece of an ethics of sustainability and place poverty reduction and animal ethics in the close surrounding as being augmentations of FP. It thus follows that we should clearly distinguish among (a) ethical presuppositions of sustainability (as democracy, peace and the like), (b) the overall moral cluster (FP, absolute poverty, animal ethics), (c) original FP as centerpiece, and d) the many pressing moral and justice problems that are external to a theory of sustainability. (There are many moral issues that deserve and attract moral attention, such as health care, immigration, education, welfare policies, taxation, gender relations, bribery, drugs.). This distinctiveness requires a political division of institutions. It is not unfair against poor persons and sentient creatures to focus on FP institutions, as long as other institutions address other moral topics.

\section{Competing Theories of Justice}

\subsection{Institutionalizing Distributive Justice}

Any ethical theory of justice is, as we have known since Aristotle, a complex enterprise since there are several dimensions of justice: political justice, distributive justice, corrective justice. These dimensions are augmented by the distinction between scope, pattern and measure ("currency") of justice [17], which is clearly relevant to the dimension of distributive justice. While a connection between a system of human rights and democracy is adopted by most ethicists in the dimension of political justice [9], the dimension of distributive justice is more controversial since it affects property rights and touches the problem of how to relate inequality and justice. This dimension is essentially connected to a theory of societal and cultural goods ("Güter") that have different cultural meanings [18]. Even if one believes in some Rawlsian "primary goods" as being all-purpose means, the distribution of 
many other goods cannot abstract away their cultural significance. This is true also for natural goods. However, since we cannot know the cultural significance of natural goods in a future world, the cultural values of nature obviously must be assessed (perhaps, in terms of "ecosystem services") from within the present time. Thus, some paternalism seems to be essentially involved in the FP [19]. What appears as paternalism at the first glance may, however, be re-interpreted as future actualization of contemporary moral debates. It seems not completely arbitrary to assume that present moral reasoning will be actualized in moral education and will be present in the future as attitudes, convictions, and moral and cultural traditions. There is a necessitation in all ethics to suppose such actualization. Our best moral insights and arguments are in some sense "immortal" if they establish moral traditions. Institutionalization would not be the project of one single generation but would be a vivid moral tradition to be continued. If we take the overall discourse in environmental ethics as an emerging moral tradition that will be alive in the future, we are entitled to prolong our environmental values into the future.

\subsection{The Capability Approach}

There is a plurality of competing theories of justice. The capability approach (CA) competes with Rawlsian approaches within the field of justice. For the purpose of this article, it must be sufficient to compare both approaches. These and other underlying ethical approaches are not neutral with respect to institutionalization.

CA comes in two variants, given in the many writings of A. Sen and M. Nussbaum [16,20]. CA is appealing from the moral point of view since it is universalistic and it takes humans as practical beings longing for a good life. It provides some moral ideas about a life worthy of the human being, a concept of development as freedom and a system of moral entitlements in terms of capabilities. CA has a clear position with regard to scope (universalism), pattern (sufficientarism) and currency (capabilities) of justice. All persons should reach sufficiently high standards of all crucial capabilities. If this is not the case, injustice occurs. CA allows differentiating the ethical notion of the good into (a) a general anthropological, and (b) a specific cultural dimension. This distinction sheds new philosophical light upon the relationship between the (axiological) "good" and the (moral) "right". Under the CA, the general human good is prior to the moral right, while the moral right is prior to the cultural good of specific lifestyles. (This idea emerged from discussions with Lieske Voget-Kleschin. The basic idea is hers.) CA has a hard universalistic ("essentialist") core, while leaving much room for cultural interpretation, discourse and personal freedom. CA commits states to social policies which may improve and strengthen the capabilities of all individuals with some focus on disadvantaged groups. Capabilities are entitlements which support political right-claims. "Capability, not actual functioning, should be the goal of public policy" [21]. For these and other reasons, CA has attracted many scholars (Robeyns) and influenced high-level political declarations within the UN system. Even within the ethics of sustainability, CA is currently the most prominent approach. (The theory of strong sustainability also made use of the CA with respect to an absolute inter- and intragenerational standard of justice [22].) At a second glance, however, it seems fair to mention the following problems of CA. (The following critical comments rely on Pogge's important article [23].)

Within CA, injustice occurs if not all persons can realize all their capabilities up to a given threshold. The famous list of ten capabilities as presented by Nussbaum [24] does, as such, not 
determine any specific threshold up to which any human being is entitled to realize the capability at stake. To Nussbaum, however, the list is already "an account of the second threshold" [21]. (The first threshold is about a life that counts as human, while the second threshold determines a good life. I only deal with the second threshold.). Indeed, there are some axiological attributes in the list, as "a human life of normal length," "good health," "adequate shelter," and the like. Nonetheless, such attributes do not determine any threshold. As Sen argues, Nussbaum's list implies only "minimal rights against deprivation" [25]. The conceptual way from a mere list to a robust system of thresholds is thorny and, with some likeliness, will be essentially contested on cultural, political, and economic grounds. Nussbaum concedes the necessitation for interpretation and refinement. But if such thresholds were to be determined completely on cultural and political grounds, CA would collapse back into culturalistic ethics. It seems fair to say that CA has a threshold problem.

The notion of capability is a dispositional one, sometimes defined as "effective opportunities" [26]. "Capable" roughly means "actually being able to perform a course of action (which one has reason to value)." Capabilities are both freedoms and potencies. Furthermore, capabilities can be perceived either as "the power to do something" [27] or as a conjunction of internal dispositions and external circumstances or resources [28]. If so, one has to distinguish between internal and so-called combined capabilities. Entitlements can refer to both kinds of capabilities.

Capabilities have a good of their own and must be separated from other abilities, as the ability of cheating or mere physical strength. This distinction between valuable capabilities and abilities rests on moral suppositions. We furthermore must distinguish this evaluative notion of capability from its additional qualifiers ("actual," "real," "effective"). The qualifiers oppose mere formal freedom, as given in legal rights, and wish to focus on "real" ("actual", "substantive") freedom instead. The combination of the notion of capabilities and qualifiers implies the concept of "real" freedom. If one adopts the idea of "real" freedom, one can always ask: "How real is real enough?" If the qualifiers are to be determined by thresholds, and if there are no thresholds within the CA yet, the qualifiers tend to become political rhetorical devices with respect to policies of empowerment. All in all, capabilities serve as indicators for the extent of the (real) freedom a person has. What must be sustained in the first instance, therefore, is human freedom [29]. Institutionalization of sustainability does not refer to natural resources in the first instance but to institutions as human rights, democratic life and social systems of education, health care and public infrastructure.

Capabilities cannot be observed directly. Only human behavior can be observed directly; the capability set of a human individual must be supposed and indirectly assessed. The crucial "object" being the final goal of justice, is invisible. If so, there is an invisible disposition at the heart of a theory of justice which is surrounded by a multitude of influential factors and circumstances to be assessed by social sciences. The societal surrounding that constitutes and shapes capabilities includes natural, cultural, economic, familiar, psychological factors. The specific force of these bundles of factors upon an individual's capability set is hard to determine and will remain, in part, speculative since individuals are never fully transparent to others (and not even to themselves).

The stylized non-dynamic model of a person's capability set that Robeyns [30] proposed in the line of Sen's ideas, has been clearly influenced by economic schemes. One faces an economic production function with (a) resource-input, (b) the "black box" of the internal capability set and (c) the output of doings and beings (functionings). Resources (inputs) are converted by capabilities into doings and 
beings (outputs). Conversion is performed differently by different individuals. The performance of how to convert is intrinsically determined by the invisible capability set and by many circumstances. Sen points out that $\mathrm{CA}$ allows taking into account "the parametric variability in the relation between the means, on the one hand, and the actual opportunities, on the other" [25]. This parametric relation might be useful for explanations within social sciences, but the ethical and distributive implications of the conversion problem remain unclear. Should resource inputs increase if individuals convert badly and should inputs be shortened if individuals perform efficiently?

CA is highly "idio-logic" in the sense that the real capabilities of specific individuals are to be assessed. Individuals as such count in CA. Therefore, CA moves between (folk) psychology and single stylized narratives which shall serve as paradigm examples. No one might seriously oppose the claim that disabled people need wheelchairs while healthy people do not. However, there are far more contingencies in individual lives, such as caring in early childhood, good fortune in schooling or features of family life. In any case, CA must immerse in the contingencies and randomness of single biographies in different natural and cultural settings. With respect to future individuals, the constituencies and shapings of capabilities remain largely speculative. Since capabilities are formed and shaped in quite early stages in child development, such as trust in oneself, CA is closer to psychology than to environmentalism.

CA sharply opposes resourcism. It implies a "fundamental shift" from means to actual opportunities [31]. To CA, natural resources are mere means and of instrumental value with respect to the currency of justice, namely capabilities. Sen opposes "resource fetishism" which occurs if resources are addressed without clear reference to capabilities. In some sense, it is true that within a broadly anthropocentric concept of sustainability there is value in nature only if humans are benefitted by some welfare effects of nature. CA, however, shifts the burden of proof to nature conservation if conservation (preservation, restoration) is justified only as long as a clear contribution to capabilities can be demonstrated. Otherwise, the criticism against resource fetishism applies. Even if one takes a closer look at the capability to live with concern for a world of nature (Nussbaum) [16], it remains unclear how much nature is required to perform this capability up to the threshold of justice. To CA, the intra- and intergenerational distribution of natural resources must be assessed with respect to (unobservable) capability sets and unspecific thresholds. What are species and wild places good for in terms of capabilities? How do marine biodiversity or restoration activities affect capabilities? The relationship between natural resources and capabilities remains open in many cases. The attempts to re-integrate environmentalism and nature conservation into a CA-based theory of sustainability have been, so far, of limited success (The idea of conceiving basic ecological conditions such as "meta-capabilities" [32] is rather unconvincing.). It might suffice for $\mathrm{CA}$ to bequeath only critical natural capital to future generations.

With respect to institutionalization, the direct moral and political concern for human capabilities implies an agenda of how to organize, design and arrange different ("emancipatory") policies of empowerment. Such policies of empowerment of capabilities refer primarily to poor or impoverished societal strata whose members may live below some threshold levels. In the international arena, CA is primarily concerned with nourishment, shelter, medical care, participation in social life, gender equity, care for the elderly and the like. Such organized policies of empowerment may be widened to capabilities such as cooking, gardening, fixing things, playing music, performing physical exercise, a 
relearning of playful activities, and even enjoying leisure. Such policies to empower people in terms of capabilities must be implemented, administered, and financed. This agenda of empowerment to be institutionalized is a vast field on its own. (Liberals may reject it as a pathway into a leftist superwelfare and nanny state. To liberals, the rhetoric of emancipatory empowerment might correspond to the sober realities of soft dependency and subtle coercion within large welfare systems. I leave this kind of criticism aside.) If $\mathrm{CA}$ is to be taken seriously, such an agenda deserves some priority over resource-oriented agendas of FP because direct concerns of justice are overriding indirect concerns. I do not oppose such policies of empowerment, but I wonder about the relationship between such policies and an FP agenda in a non-ideal world of scarce moral resources and limited moral attentiveness.

To sum up briefly: CA, by its intrinsic logic, will focus on the topics of poverty reduction and, in Nussbaum's variant [33], animal ethics in the overall cluster of sustainability ethics, while a resourcist FP seems a secondary and derivative concern at best and "resource fetishism" at worst. The focus is clearly on social and welfare-state policies. There is no conceptual relation between CA and strong sustainability.

\subsection{The Rawlsian Approach}

The Rawlsian construction of the original position gives a theoretical device which allows one to regard principles as just, if they might have been adopted freely (and with knowledge about alternative sets of principles) in such an original position ("veil of ignorance") [34]. Rawls's theory focuses on the basic structure of society seen as a scheme of cooperation which requires the fulfillment of some functional values (coordination, efficiency, cohesion). The theory is centered on single states and not on international relations, though it can be broadened beyond states [35]. Under the veil of ignorance that covers any social position, free, detached, envy-free and reasonable persons would adopt (a) a principle of personal freedom which constitutes a system of liberty rights including political rights, (b) a principle of fair equality of opportunities to reach attractive positions in a given society, (c) a principle of solidarity with the least advantaged group (within a system of cooperation) ("principle of difference") and (d) a principle of intergenerational fairness. The first three principles are ranked lexicographically, while the fourth principle serves as a constraint over the principle of difference [36]. These four principles are constitutive elements of a just basic structure of a given society. While the first three principles go back to the tradition of the French revolution (liberté, egalité, fraternité), the fourth principle has been often overlooked in its significance for a comprehensive Rawlsian theory of justice and for an ethics of sustainability. (Since the theory of justice is only one field within the overall realm of practical reasoning, there are many other sources of moral action beyond the field of justice.) To Rawls, this fourth principle has something to do with fair savings and investments by which future generations are benefitted. The problem of a fair saving rate should not be subject to altruistic preferences of grandmothers to their grandchildren but should be part of the basic structure of a just society. Natural inclinations to bequeath goods to one's descendants must be overcome in a theory of justice.

$\S 44$ [37] within the "Theory of Justice", however, entails several flaws that have their root cause in a confusion about "timing." This confusion can be resolved [38] without modeling persons behind the 
veil as being representatives of family lines, as Rawls [39] did. Another problem lies in the concept of real capital, which is supposed in the precept of an intergenerational fair saving schedule. On the one hand, Rawls defines the notion of real capital so broadly as to include natural capital, while on the other hand he focuses on monetary savings and investments in manmade capital. Although Rawls sometimes mentions environmental pollution, he does not address the role of nature within intergenerational fairness. Thus, natural capital is not mentioned by Rawls but, in a sympathetic reading, would fall under his notion of real capital. Most environmental economists would agree that natural capital is a type of real capital that provides (ecological) services by which humans are being benefitted in many ways. Since some scientifically based general knowledge remains intact behind the veil of ignorance, general ecological knowledge must or may be supposed in the original position. Reasonable people behind the veil of ignorance may know that nature provides several types of services, such as provisioning, regulating, and cultural services, but do not know what role such services of nature may play in their individual concept of the good. If so, they cautiously might opt for more conservation and restoration since they, as real individuals, may be benefitted highly by the cultural values of nature (such as beauty or recreation). Under this interpretation, one can conceive the fourth principle as an overall fair intertemporal bequest package. Such a concept directly turns into the (clearly resourcist) FP question: "What to sustain?" Citizens and policy-makers are confronted with this question within a fair basic structure of society. Even if the persons in the original position had some broad insights into the reliance of human systems upon nature and knew about ecosystem services, this knowledge would remain too unspecific to answer the question "What to sustain?" This question cannot be resolved behind the veil of ignorance anymore (The fourth principle does not imply any answer to the political question how the relationship between private and public bequests should be determined in a given society and which system of property rights may best serve the idea of sustainability.).

\section{The Concept of Strong Sustainability}

Citizens of different societies must specify the basic question "What to sustain?" with respect to different types of capital (manmade capital, human capital, natural capital). They should neither leave the answer to experts nor to markets. Any answer will rest on assumptions which are contested within the ongoing theoretical debate on "weak," "intermediate" and "strong" sustainability [40,41], such as substitution, technological progress, discounting, and compensation. This debate constitutes a vast array of claims, arguments, refutations, scientific evidence, models, and the like. Given discursive freedom, different just societies may reach different conclusions about the amount of natural capital that should be preserved, about criticality of natural capital, about the contribution of ecological services to societal welfare, about the rate of discount, and about the degree of substitutability between different types of capital. In the first instance, any fair society is entitled to adopt whatever concept of sustainability they believe to be "superior" or "more favorable". If the discursive procedure has been fair, the outcome has to be respected fully. Institutionalization, then, will vary according to the concept being chosen by different societies. Any just or decent society has to respect such a choice being made in another society. (This Rawlsian picture is clearly restricted to the relation between national states. It does not refer to global environmental regimes. This abstraction will be removed in the final section.) 
Matters look different, however, if one believes that the debate between weak, intermediate and strong concepts of sustainability has provided some robust results in favor of strong sustainability $[2,4,40]$. Environmental discourses give some reasons to conceive the question about substitutability of natural capitals in a broad way. The question is not only "Can we substitute nature by technical means?" nor "Can we substitute natural resource inputs for production?", but also "Do we really wish to substitute natural environments by more artificial ones if nature has many non-material welfare effects on many of us?" With respect to nature conservation, single groups within civil society may argue from within strong environmental traditions which should continue [42], argue with respect to eudaimonistic values or even with moral convictions about inherent moral values in nature (Eckersley) [43]. There are arguments about risk and precaution with respect to critical natural capital (Ekins) [44,45]. If intermediate sustainability requires maintaining critical natural capital and if there are large uncertainties about criticality, we should better adopt a safe minimum standard (Ciriacy-Wantrup) [46]. If we ask ourselves "How safe is safe enough?" we may conclude that we should maintain prima facie the remaining stocks of natural capital. If we take the uncertainties about the values, conviction, and attitudes of future persons seriously we should not rule out the possibility that future people may have rediscovered the biophilic disposition of humans (Wilson) [47] and shaped this disposition in new cultural ways to relate to humans. Even supporters of the CA might argue that the capability of being able to live with a concern for a world of nature, including animals and plants [24], might be actualized to high levels by both present and future individuals. Studies that exploit the ecosystem services approach may come to the conclusion that cultural values of nature contribute far more to social welfare than conventional economic wisdom has believed (Jax et al.) [48]. To hold natural capital constant over time also has an intragenerational aspect since contemporary groups of "naturalists" are benefitted by such policy [49].

These arguments back and motivate a reasonable and prudent choice in favor of strong sustainability $[2,50]$. Such choice constitutes a general collective prima facie obligation with respect to different stocks of natural capital. (This obligation does not imply a permission to neglect other types of capital.) It seems reasonable to interpret this collective obligation as a general rule to hold natural capitals (natural goods) at least constant over time (constant natural capital rule: CNCR). Therefore, the concept of strong sustainability is rule-based and, as such, can and should be institutionalized and organized within a just society. CNCR, being the basic rule of strong sustainability, gives content to the fair bequest package and must be specified to a comprehensive system of rules ("management rules"). The establishment of a rule-based governmental and governance scheme which specifies the CNCR is the core meaning of institutionalizing strong sustainability. (Note that this approach sees collective duties as prior. Personal duties to behave "sustainably" fall under the guideline of sufficiency. They are mostly imperfect duties.) CNCR must be specified to a system of rules. If so, the route for further institutionalization of a rule-based concept of strong sustainability has been opened. Now it must be paved.

\section{Steps toward Institutionalization: A Rawlsian Perspective}

The political philosophy of Rawls also deals with specific institutions. The principles must be actualized by institutions and organizations in a way that reinforces the underlying conception of 
justice and motivates persons to contribute to it by commitments and fair shares. To Rawls, the abstractions of the original position are to be removed step by step and persons return to the real world. There are some unexplored parallels between Hegel's idea that a substantial political order (Hegel: "state") "actualizes" freedom and Rawls's idea that the principles of justice must be realized by way of institutions. In his theory, Rawls distinguishes a set of branches of government which must be institutionalized with respect to distributive justice in any just modern society (§ 43 [51]) (It must be noted that a problem occurs in Rawls, since he deals with these branches $(\S 43)$ before he argues in favor of a fair saving schedule ( $\S 44)$ [37]. Thus, the fourth principle is underrepresented in the branches.): "Without the proper arrangement of these background institutions the outcome of the distributive process will not be just" [39]). There is no just modern state without these governmental branches which entail specific rules, objectives, finance and administrative organizations. They are to fulfill specific tasks within a well-ordered system of cooperation. These branches are robust in their principled core and flexible in their political programs. Their general tasks specify into problem solving within the routines of a given branch (welfare policies, education, taxation, collective goods). If so, at least one branch of government should address the fourth principle. (It might be promising to compare Rawls's system of branches with Hegel's theory of the modern state, especially with administration, but such comparison is beyond the scope of this paper.)

To Rawls, there should be a governmental branch for protection and restoration of public goods ("exchange branch") which, in principle, could be devoted to sustainability policies and even to animal protection. Rawlsians can and should conceive an institutionalized branch which is committed as governmental organization to the fourth principle of justice and, more specifically, to strong and rulebased sustainability and its FP. The collective moral obligations implied in the idea of sustainability are mediated by such a branch as it proceeds to more specific programs (laws, rules, objectives, administration, and systems of incentives and disincentives). This branch serves as an institution of checks and balances against other branches which deal with other kinds of social policies. (Poverty reduction shall be addressed by another branch of a just society that implements the principle of difference. To Rawls, this principle presupposes the entitlement of any human being to fulfill basic needs. In wealthy societies, the principle of difference ("minimax") provides poor persons with more resources than a mere basic-needs-principle.) Any just state has to establish a sustainability branch whose primary task is to conceive a comprehensive national sustainability strategy. If so, there is no contradiction between political liberalism and sustainability. The contrary is true: without institutions for sustainability, political liberalism is essentially incomplete. The specific design of a country's sustainability strategy, of course, depends on the very concept of sustainability being chosen. For the rest of this article, I suppose a choice in favor of strong sustainability and its system of rules.

A Rawlsian "sustainability" branch can adopt the rules of strong sustainability and implement them in different fields of action via specific laws, agendas, programs, and organizations. Crucial rules within such system are the investment rule and the management rules. The investment rule deals with the past depletion of natural capitals. Often, such depletion and degradation is to some extent reversible, especially under favorable environmental boundary conditions, as fertile soils, germ seeds, and water. If the CNCR has been ignored or violated in the past for whatever reasons, there was a period of underinvestment in natural capital (Periodical underinvestments in machinery and infrastructure can be compensated by intensified investment, as it was the case after the collapse of 
communism in Eastern Germany.). The very idea of a fair bequest package entails obligations to fix such underinvestment if the current society can afford such investments. If so, investments in natural capital, then, shall reach a level from which on the CNCR applies. What counts as investments in natural capital from a more economic perspective, turns out to become ecological restoration from a more scientific perspective. Thus, the wealthy countries in the northern hemisphere have reasons to restore their own natural environment and may support restoration activities in other countries and regions. In any case, one office within this branch should be devoted to foreign environmental affairs, such as trade, tourism, and investments.

Other rules are about replacing fossil fuels by renewable energies, reducing pollution below critical loads, respecting the natural rhythms of living systems, holding yields of living funds below natural regeneration rates, and avoiding or reducing severe environmental risks, such as climate change. Meanwhile, such management rules have been widely adopted. The implementation of such rules, however, is not trivial since it follows a "hydra" logic. If some general problem of rule specification seems to be resolved, two even more specific problems occur. At this point, rules are to be specified by policy goals and objectives. To follow a rule is, then, specified in terms of objectives. Such objectives, however, cannot be derived from rules, but might be proposed by experts and administrative bodies and must, ultimately, be fixed by policy makers or by way of administration. The specification of rules (institutions) in terms of objectives is performed by administration, monitoring, research, planning, giving directives and the like. High environmental standards are recognized in the different offices of this sustainability branch. Single offices within the branch also keep the institutional memory alive over decades.

Coming close to fields such as agriculture, forestry, fisheries, or cattle, specific administrative bodies implement specific laws and directives. The more specific governmental schemes become, the higher the degree of political leeway must become since specific objectives can be derived neither from science nor from ethics. How much space does a breeding eagle really need? Do windmills impair the population size of migrating birds? How shall we design protected areas? Should 75\% of the territory of national parks be free of human utilization or might $50 \%$ be sufficient? Shall we restore a wetland even if local tourism might be impaired by mosquitoes? In such cases, traditional government schemes (law making, implementation) might be augmented by new modes of governance, as stakeholder participation, citizens' juries, or expert committees. To Rawlsians, government might be augmented by "good" governance, but cannot be replaced by modes of governance.

Finally, opportunity costs of strong sustainability should be distributed fairly. This is important, since conservation and restoration of natural capital may bring direct opportunity costs for a relatively small fraction of the population, namely in agriculture, forestry, fishery. Since strong sustainability is a political enterprise of society as a whole, these costs should be distributed fairly among the entire population. If so, the sustainability branch has to address problems of how to distribute opportunity costs of strong sustainability fairly. If there should be a mutual constraint ("proviso") between the system of sustainability rules on the one hand, and poverty reduction on the other hand, the sustainability branch should be checked by branches that address welfare policies for poor strata within societies. Such policies are governed by the principle of difference. In a well-ordered society, such 
checks and balances can become routine via horizontal policy integration being organized between different branches.

\section{Conclusion and Outlook}

Via such institutionalization, strong sustainability can, in principle, be actualized in any wellordered society. Up to this point, the Rawlsian perspective has been clearly state centered. A statecentered perspective does not have to downplay the role of international environmental regimes, NGOs, epistemic communities, and international governance schemes in our globalized world. The prospects to actualize sustainability on a global scale, however, become all too lofty if there are no solid institutional anchors within national states. In the first instance, the institutionalization of sustainability is to be grounded in national states since well-ordered and decent states have the organizational and financial capacities to implement comprehensive sustainability strategies. Under real-world conditions, however, sustainability cannot be reached in isolation. Because sustainability is, ultimately, a global topic, a state-centered perspective must be overcome.

In his "Law of Peoples", Rawls [52] himself has restricted his theory to well-established principles of international law. Global institutions for sustainable development are not mentioned by Rawls. Thus, an international equivalent to the fourth principle of justice is missing in Rawls's "Law of Peoples" [52]. As many Rawlsians have argued, one has to move beyond Rawls with respect to international affairs. The very idea of global environmental regimes is about a normative equivalent to the fourth principle of justice because these regimes deal with global bequest packages with respect to atmospheric greenhouse gas concentrations, fish stocks, biodiversity, primary forests, mires and wetlands, migrating species, etc. Since the 1970s, global environmental governance has already made some initial progress despite harsh recent failures, especially with respect to climate change. Compared to real challenges, such global environmental governance is still in its infancy. In this final section, four transnational commitments of well-ordered societies are argued for. By fulfilling these commitments, states may contribute to further progress in institutionalizing sustainability on a global scale. There is, first, a moral obligation of wealthy and well-ordered societies to take the lead. Wealthy states should act as forerunners demonstrating practically that strong sustainability is no utopia but can be actualized. By doing so, they demonstrate both a readiness and willingness to reduce both input and output of domestic industrial production ("physical degrowth"), to change lifestyles and habits ("sufficiency") and to restore their natural environments ("resilience"). Strong domestic actions will have some beneficial transnational environmental effects with respect to logging, mining, farming, and land acquisition. If so, pressure on foreign natural systems might be gradually relieved. In the course of time, domestic environmental institutions of well-ordered societies may also spread and diffuse globally.

Second, states have negative duties neither to hamper nor to compromise strong sustainable development in other countries. With the framework of moral universalism, it would be incoherent to actualize strong sustainability at home without any concern for one's external effects on other people. No fair society is entitled to produce and consume at the expense of the natural capital of another society which wishes to keep it intact. No fair society is entitled to force other people to deplete their natural capital. No state should give practical or financial support to non-sustainable activities abroad. Such duties are mainly prohibitions (negative duties), by which states should bind themselves with 
respect to foreign environmental affairs. This second duty, however, also holds for economic regimes as WTO whose rules have many environmental effects. Institutionalization and organization of selfinduced prohibitions, such as new modes of trade control, may conflict with the rules of WTO. Critical discourse on crucial topics as "like products" might be a first step in reconciling environmental and economic regimes in the longer run.

Wealthy societies which have adopted the concept of strong sustainability have, third, an imperfect positive duty to assist poor and decent societies to realize the same concept. This duty is in the spirit of Rawls's "Law of Peoples" [52]. In economic parlance, wealthy states should help others to reach the down-sliding side of the Environmental Kuznets Curve. Such imperfect duty to assist may be arranged in conjunction with traditional development aid and with additional duties to fairly compensate the damages being caused by high greenhouse-gas-emissions. It is open for further debate how a specific institutional design of such conjunction may look like. The most inconvenient challenge is to secure the moral and environmental integrity of such institutional facilities against the many incentives to misuse financial transfers.

Fully liberal and wealthy states have, fourth, a duty to champion an international system of environmental regimes and substantial protocols by which they commit themselves. This duty can be actualized in regimes as FCCC, Convention on Biological Diversity, Ramsar Convention, Convention on Migratory Species, Law of the High Sea, and the like. This duty to engage refers not only to the nice wording of soft law, which international conventions often are, but it refers to real commitments as being defined by protocols. It also refers to the transformation of UNEP into a real UN organization, comparable to UNESCO and FAO.

My final substantial claim is about competing theoretical schools in international relations. These schools compete on both positive-analytical and normative grounds. While the "neorealistic" (Hobbesian) school of thought is at some pain to explain the contemporary international order out of strategic interests of national states, it overtly presumes to face sober realities simply as they are. On normative grounds, the parochial axioms of this school shape the performance of agents who act accordingly. Thus, "raison d'etat" often becomes a self-fulfilling prophecy. The "institutionalistic" (Kantian) school of thought is, at least, on a par with neo-realism with respect to explanation and analysis. But, to ethical universalism, it is clearly superior with respect to its principles of peaceful cooperation, respect for human rights, mutual aid, and institution building beyond states. Institutionalizing sustainability beyond states will be a major challenge for decades to come. Discarding neo-realism is a necessary intellectual precondition for facing such challenge.

To sum up the presumed substance of this article: If argumentation is sound, it provides some general orientation (a) why a Rawlsian, rule-based variant of strong sustainability should be adopted, (b) how its resourcist focal perspective might be specified and (c) how such approach might be properly institutionalized on both a national and international layer of politics and policy making. Any ethical orientation should have a solid grounding. Therefore, the article has made some effort on such ethical grounding (Sections 3 and 4). Moreover, orientation should point to some directions. This has been done in Sections 5 and 6 (or so I hope). By providing such grounded and directing orientation, the article contributes to the furthering debate on how to actualize the very idea of sustainability. 


\section{Acknowledgments}

The author is grateful to two anonymous reviewers and to Margarita Berg for lingual improvements and Max Schröder for technical assistance.

\section{Conflicts of Interest}

The author declares no conflict of interest.

\section{References}

1. Hegel, G.F.W. Grundlinien der Philosophie. des Rechtes (In German), 1st ed.; Suhrkamp: Frankfurt am Main, Germany, 1971.

2. Ott, K.; Döring, R. Theorie und Praxis starker Nachhaltigkeit, 2nd ed.; Metropolis-Verlag: Marburg, Germany, 2008.

3. Ott, K. On Substantiating the Conception of Strong Sustainability; In Sustainable Development: Relationships to Culture, Knowledge and Ethics; KIT Scientific Publishing: Karlsruhe, Germany, 2011; pp. 159-174.

4. Daly, H.E. Beyond Growth: The Economics of Sustainable Development, 1st ed.; Beacon Press: Boston, MA, USA, 1996.

5. Rawls, J. The Law of Peoples; Harvard University Press: Cambridge, UK, 1999; p. 55.

6. Von Wright, G.H. Norm und Handlung Eine logische Untersuchung, 1st ed.; Scriptor Verlag GmbH and Co. KG: Königstein, Germany, 1979.

7. Klauer, B.; Manstetten, R.; Petersen, T.; Schiller, J. The art of long-term thinking: A bridge between sustainability science and politics. Ecol. Econ. 2013, 93, 79-84.

8. Muraca, B. Décroissance: A project for a radical transformation of society. Environ. Values 2013, 22, 147-169.

9. Habermas, J. Between Facts and Norms, 1st ed.; Polity Press: Cambridge, UK, 1996.

10. Carlowitz, H.C. Sylvicultura Oeconimca: Hauswirthliche Nachricht. und Naturmäßige. Anweisung zur Wilden Baum-Zucht (In German), Facsimile reproduction; Kessel: Remagen, Germany, 2012.

11. Ott, K. A Modest Proposal about How to Proceed in Order to Solve the Problem of Inherent Moral Value in Nature. In Reconciling Human Existence with Ecological Integrity; 1st ed.; Earthscan: London, UK, 2008; pp.39-59.

12. World Commission on Environment and Development. Our Common Future, 1st ed.; Oxford University Press: Oxford, UK, 1987; pp. 1-383.

13. World Commission on Environment and Development. Our Common Future, 1st ed.; Oxford University Press: Oxford, UK, 1987; p. 43.

14. World Commission on Environment and Development. Our Common Future, 1st ed.; Oxford University Press: Oxford, UK, 1987; p. 45.

15. Voget-Kleschin, L. Sustainable Food Consumption? Claims for Sustainable Lifestyles in between Normative and Eudaimonistic Issues. The Example of Food Production and Consumption. PhD. Thesis, Ernst-Moritz-Arndt-Universität, Greifswald, Germany, 2013. 
16. Nussbaum, M. Frontiers of Justice, 1st ed.; Belknap Press: Cambridge, MA, USA, 2006.

17. Page, E.A. Intergenerational Justice of What: Welfare, Resources or Capabilities? Environ. Polit. 2007, 3, 453-469.

18. Walzer, M. Spheres of Justice, 1st ed.; Blackwell: Oxford, UK, 1983.

19. Norton, B. The Ignorance Argument: What Must We Know to be Fair to the Future? In Economics, Ethics, and Environmental Policy, 1st ed.; Blackwell Publishing: Oxford, UK, 2002; pp. 35-52.

20. Sen, A. Development as Freedom, 1st ed.; Oxford University Press: Oxford, UK, 1999.

21. Nussbaum, M. Introduction. In Women, Culture and Development: A Study of Human Capabilities, 1st ed.; Clarendon Press: Oxford, UK, 1995; p. 82.

22. Ott, K.; Döring, R. Theorie und Praxis Starker Nachhaltigkeit, 2nd ed.; Metropolis-Verlag: Marburg, Germany, 2008.

23. Pogge, T.W. How Can the Capabilities Approach Be Justified? Phil. Top. 2002, 2, 167-228.

24. Nussbaum, M. Capabilities as Fundamental Entitlements: Sen and Social Justice. Fem. Econ. 2003, 9, 33-59.

25. Sen, A. Human rights and capabilities. J. Human Dev. 2005, 2, 151-166.

26. Robeyns, I. The Capability Approach: A theoretical survey. J. Human Dev. 2005, 1, 93-117.

27. Sen, A. What do We Want from a Theoy of Justice. J. Phil. 2006, 53, 215-238.

28. Christen, M. Die Idee der Nachhaltigkeit (In German), 1st ed.; Metropolis Press: Marburg, Germany, 2013; p. 230.

29. Sen, A. Continuing the Conversation. Fem. Econ. 2003, 9, 319-332.

30. Robeyns, I. The capability approach: A theoretical survey. J. Human Dev. 2005, 1, 98.

31. Sen, A. The Idea of Justice, 1st ed.; Allen Lane: London, UK, 2009; p. 253.

32. Holland, B. Justice and the environment in nussbaum's ,capability approach: Why sustainable ecological capacity is a meta-capability. Polit. Res. Q. 2008, 61, 319-332.

33. Nussbaum, M. Frontiers of Justice, 1st ed.; Belknap Press: Cambridge, MA, USA, 2006; pp. 325-405.

34. Rawls, J. A Theory of Justice, 1st ed.; Clarendon Press: Oxford, UK, 1972; pp. 136-142.

35. Pogge, T.W. How can the capabilities approach be justified? Phil. Top. 2002, 2, 167-228.

36. Rawls, J. A Theory of Justice, 1st ed.; Clarendon Press: Oxford, UK, 1972; p. 292.

37. Rawls, J. A Theory of Justice, 1st ed.; Clarendon Press: Oxford, UK, 1972; pp.284-293.

38. Ott, K. Essential Components of Future Ethics. In Ökonomische Rationalität und praktische Vernunft Gerechtigkeit, Ökologische Ökonomie und Naturschutz. Festschrift für Ulrich Hampicke (In German), 1st ed.; Königshausen und Neumann: Würzburg, Germany, 2004; pp. 83-108.

39. Rawls, J. A Theory of Justice, 1st ed.; Clarendon Press: Oxford, UK, 1972; p. 275.

40. Neumayer, E. Weak versus Strong Sustainability. Exploring the Limits of Two Opposing Paradigms, 1st ed.; Edward Elgar Publishing Limited: Cheltenham, UK, 1999.

41. Atkinson, G.; Dubourg, R.; Hamilton, K.; Munasinghe, M.; Pearce, D.; Young, C. Measuring Sustainable Development Macroeconomics and the Environment, 1st ed.; Edward Elgar Publishing Limited: Cheltenham, UK, 1997.

42. Sagoff, M. The Economy of the Earth, 1st ed.; Cambridge University Press: Cambridge, UK, 1988; pp. 146-170. 
43. Eckersley, R. Liberal democracy and the rights of nature: the struggle for inclusion. Environ. Polit. 1995, 4, 169-198.

44. Ekins, P. The Practical Application of the Concept of Critical Nature Capital and Strong Sustainability. In Sustainability, Natural Capital and Nature Conservation, 1st ed.; MetropolisVerlag: Marburg, Germany, 2009; pp. 95-115.

45. Ekins, P.; Simon, S.; Deutsch, L.; Folke, C.; de Groot, R. A framework for the practical application of the concepts of critical natural capital and strong sustainability. Ecol. Econ. 2003, $44,165-185$.

46. Ciriacy-Wantrup, S.V. Natural Resource Economics: Selected Papers, 1st ed.; Westview Press: Boulder, CO, USA, 1985.

47. Wilson, E.O. Biophilia, 1st ed.; Harvard University Press: Cambridge, MA, USA, 1984.

48. Jax, K.; Barton, D.N.; Chan, K.M.A.; de Groot, R.; Doyle, U.; Eser, U.; Görg, C.; Gómez-Baggethun, E.; Griewald, Y.; Haber, W.; et al. Ecosystem services and ethics. Ecol. Econ. 2013, 93, 260-268.

49. Hampicke, U. Naturschutz als Problem der Gerechtigkeit unter Zeitgenossen. In Lebenswelt und Wissenschaft (In German), 1st ed.; Felix Meiner Verlag: Hamburg, Germany, 2011; pp. 1215-1226.

50. Ziegler, R.; Ott, K. The quality of sustainability science: A philosophical perspective. Sustain. Sci. Pract. Pol. 2011, 1, 1-14.

51. Rawls, J. A Theory of Justice, 1st ed.; Clarendon Press: Oxford, UK, 1972; pp. 274-284.

52. Rawls, J. The Law of Peoples; Harvard University Press: Cambridge, MA, USA, 1999.

(C) 2014 by the authors; licensee MDPI, Basel, Switzerland. This article is an open access article distributed under the terms and conditions of the Creative Commons Attribution license (http://creativecommons.org/licenses/by/3.0/). 